\title{
Polyunsaturated Fatty Acid Supplementation Alters Proinflammatory Gene Expression and Reduces the Incidence of Necrotizing Enterocolitis in a Neonatal Rat Model
}

\author{
JING LU, TAMAS JILLING, DAN LI, AND MICHAEL S. CAPLAN
}

Evanston Northwestern Healthcare Research Institute [J.L., T.J., D.L., M.S.C.], Evanston, Illinois, 60201; Department of Pediatrics [J.L., T.L., M.S.C.], Northwestern University Feinberg School of Medicine, Chicago, Illinois, 60614

\begin{abstract}
Although supplementation of preterm formula with polyunsaturated fatty acids (PUFA) has been shown to reduce the incidence of necrotizing enterocolitis (NEC) in animal models and clinical trials, the mechanisms remain elusive. We hypothesized that the protective effect of PUFA on NEC may be due to the ability of PUFA to suppress Toll-like receptor (TLR) 4 and platelet-activating factor receptor (PAFR) gene expression (molecules that are important in the pathogenesis of NEC) in epithelial cells. To investigate the efficacy of different PUFA preparations on NEC in a neonatal rat model, we compared the incidence of NEC among the four PUFA supplemented groups-A: arachidonic acid and docosahexaenoic acid (AA+DHA), B: egg phospholipids (EP), C: DHA, and D: control without PUFA. PUFA supplementation reduced the incidence of NEC and inhibited intestinal PAFR and TLR4 gene expression compared with the controls. To validate the in vivo observations, IEC-6 cells were exposed to PAF after pretreatment with AA or DHA. Both AA and DHA supplementation blocked PAF-induced TLR4 and PAFR mRNA expression in these enterocytes. These results suggest that PUFA modulates gene expression of key factors involved in experimental NEC pathogenesis. These effects might in part explain the protective effect of PUFA on neonatal NEC.
\end{abstract}

(Pediatr Res 61: 427-432, 2007)

$\mathrm{N}^{\mathrm{E}}$ EC is the most common acute gastrointestinal disease in neonates. Risk factors of prematurity, enteral feeding, hypoxia and/or intestinal ischemia, and bacterial colonization have been associated with the development of neonatal NEC $(1,2)$. One of the key inflammatory mediators associated with NEC is PAF. Studies have shown that PAFR blockade or enhanced intestinal PAF degradation via PAF acetylhydrolase (PAF-AH) supplementation reduces the incidence of NEC in a neonatal rat model, and this experimental model resembles the clinical and pathologic features quite similar to human neonatal NEC $(3,4)$.

Supplementation of preterm formula with PUFA has generated significant interest in recent years and now appears to be the standard of care. A previous randomized, controlled clinical trial showed that PUFA supplementation for preterm infants reduced the incidence of NEC (5). Nonetheless, sub-

Received August 25,, 2006; accepted November 11, 2006.

Correspondence: Michael S. Caplan, M.D., Professor of Pediatrics, Evanston Hospital, 2650 Ridge Ave, Evanston, IL 60201; e-mail: mca113@northwestern.edu

Supported by National Institutes of Health grants \#HD37581 and \#AI058128, and Wyeth Nutritional International.

DOI: $10.1203 /$ pdr.0b013e3180332ca5 sequent trials have not substantiated this important reduction of NEC incidence with PUFA supplementation (6). Despite the inconsistency, the mechanism by which PUFA might alter the incidence of NEC in these clinical studies remains elusive. We previously reported that PUFA supplementation reduced the incidence of NEC in an experimental neonatal rat model of $\mathrm{NEC}$, and that AA and DHA supplementation in the formula may have beneficial effects on epithelial cell integrity by reducing bacterial or endotoxin translocation and/or reducing mucosal PAF synthesis and receptor activation (7). In vivo studies have demonstrated that $\mathrm{n}-3$ fatty acids protected mice from hypoxia-induced bowel necrosis by directly inhibiting endogenous PAF production and leukotriene B4 production (8). In addition, dietary supplementation of eicosatrienoic acid and DHA suppressed PAF generation in mouse peritoneal cells (9). Furthermore, DHA has been shown to reduce lipopolysaccharide (LPS)-induced IL-6 production (10). LPS derived from Gram-negative bacteria is a dominant ligand for TLR4. Recent evidence showed that PUFA inhibited nuclear factor (NF)- $\kappa \mathrm{B}$ activation and COX-2 expression induced by LPS or lipopeptide (TLR2 agonist) in macrophages (11). Therefore, there may be multiple pathways whereby PUFA impact intestinal inflammation and necrosis.

In the current study, our goal was to first identify the active ingredient in the supplementation by comparing three preparations of PUFA, i.e. AA and DHA, egg phospholipids, and DHA alone in preterm formula on the development of NEC. Secondly, we sought to determine the underlying mechanisms responsible for the effects of PUFA on intestinal injury in NEC using the in vivo neonatal rat model and in vitro intestinal epithelial cells. We report here that all PUFA supplementations reduced the incidence of NEC in our neonatal rat model of NEC. The pathomechanisms may include the ability of PUFA to suppress TLR4 and PAFR gene expression in epithelial cells.

\section{MATERIALS AND METHODS}

Animal model. The neonatal Sprague-Dawley rat model of NEC used in this study was well described previously, and included asphyxia twice daily

Abbreviations: AA, arachidonic acid; DHA, docosahexaenoic acid; NEC, necrotizing enterocolitis; PAF, platelet-activating factor; PAFR, platelet-activating factor receptor PUFA, polyunsaturated fatty acids; TLR, Toll-like receptor 
Table 1. Fatty acid profile of low birth weight formulas for NEC study

\begin{tabular}{lccrc}
\hline Diet/fatty acid & $\begin{array}{c}\text { A } \\
\text { BT-501 }\end{array}$ & $\begin{array}{c}\text { B } \\
\text { BT-517 } \\
\text { composition }\end{array}$ & $\begin{array}{c}\text { C } \\
\text { BT-519 } \\
\text { (AAHA) }\end{array}$ & $\begin{array}{c}\text { D } \\
\text { BT-520 } \\
\text { (egg phospholipid) }\end{array}$ \\
\hline C8:0 & $7.4 *$ & 12.2 & 10.6 & 10.6 \\
C10:0 & 4.6 & 5.8 & 5.0 & 4.9 \\
C12:0 & 10.5 & 11.7 & 10.4 & 10.6 \\
C14:0 & 4.8 & 4.9 & 4.7 & 4.6 \\
C16:0 & 14.5 & 12.2 & 14.4 & 14.7 \\
C16:1w7 & 0.2 & 0.3 & 0.2 & 0.1 \\
C18:0 & 3.6 & 4.9 & 3.7 & 3.7 \\
C18:1w9 & 33.9 & 29.5 & 32.2 & 32.3 \\
C18:1w7 & 0.6 & 0.7 & 0.6 & 0.6 \\
C18:2w6 & 16.2 & 14.4 & 15.5 & 15.5 \\
C18:3w3 & 1.5 & 1.2 & 1.5 & 1.4 \\
C20:0 & 0.3 & 0.2 & 0.3 & 0.3 \\
C20:1w9 & 0.2 & 0.2 & 0.2 & 0.2 \\
C20:4w6 & 0.69 & 0.71 & ND & - \\
C22:5w6 & ND & 0.2 & ND & - \\
C22:6w3 & 0.54 & 0.54 & 0.5 & - \\
C24:0 & 0.1 & 0.1 & 0.1 & 0.1 \\
C24:1w9 & 0.1 & 0.1 & 0.1 & 0.1 \\
\hline
\end{tabular}

* Data represented as percentage of total fat.

with formula feeding through an orogastric tube every $3 \mathrm{~h}$ (7). Neonatal rats were monitored (approximately 48-72 h) until clinical signs of NEC occurred. At the time of distress or at $72 \mathrm{~h}$, pups were euthanized and intestines were obtained for histologic analysis and investigation of pathophysiological mechanisms related to NEC. All animal procedures were reviewed and approved by the Evanston Northwestern Healthcare Institutional Animal Care and Use Committee.

PUFA supplementation in neonatal rat model of NEC. Neonates were randomly assigned to three treatment groups and one control group. The fatty acid compositions of control formula and the PUFA-supplemented formulas given to different groups are listed in Table 1. Control neonatal rats received a formula previously used for human low birth weight infants with no long-chain PUFA supplementation (D: Control formula BT-520, Wyeth Nutritionals International, Philadelphia, PA). Experimental diets consisted of control formula supplementation with A: AA+DHA (BT-501), B: egg phospholipids (EP, BT-517), or C: only DHA (BT-519) at a level of $0.7 \%$ AA and/or $0.5 \%$ DHA as a percentage of total fatty acids. Total fat content in the formula is $26-27 \%$ by weight. The formulation of the AA+DHA and DHA preparations contain PUFA from algal oils produced by Martek Biosciences Corporation (Columbia, MD). Separation of the oil fraction was prevented by homogenization of the oil blend at $2500 \pm 200 \mathrm{psi}$ total and immediate lyophilization to $3 \%$ moisture. EP formula provides the same amount of AA and DHA provided as phospholipid from Ovothin 160 (Degussa BioActives LLC, Waukesha, WI).

Intestine sample collection. Neonatal rat intestinal samples were used for histologic analysis and RNA isolation. For histologic analysis, the whole gut was grossly cut into halves. One half of the obtained intestine was fixed in $10 \%$ formalin. The other half was freshly frozen in liquid nitrogen and stored at $-80^{\circ} \mathrm{C}$ for analysis. If segmented samples were collected, the whole intestine was linearized first in ice-cold normal saline solution. Duodenum, jejunum, ileum, and colon segments were then separately frozen in liquid nitrogen and stored at $-80^{\circ} \mathrm{C}$ for later RNA extraction.

Histology. Formalin-fixed whole intestines were embedded in paraffin and sectioned at $5 \mu \mathrm{m}$. Sections for measurement of NEC severity of intestinal histology were stained with hematoxylin and eosin $(\mathrm{H} \& \mathrm{E})$, and scored by a blinded observer as previously described (12). Briefly, intact villi received a score of 0 , sloughing of epithelial cells on villous tips was assigned a score of 1 , and mid-villous damage was scored as 2 . NEC score of 3 was assigned to sections with complete villous necrosis, and 4 indicated transmural necrosis. Scores were determined based on the highest score observed in any particular specimen.

Quantitative real-time reverse-transcription PCR (RT-PCR). Transcription levels were determined using quantitative real-time RT-PCR and GAPDH as a housekeeping gene reference. RNA was isolated from whole tissue samples or segmented intestine samples using RNA STAT-60 reagent (TEL-TEST, INC, Friendswood, TX). RNA levels were evaluated by OD measurement at $260 \mathrm{~nm}$. Only samples with A260/280 >1.8 were used in this study to ensure total RNA quality (mRNA quality was assessed by electrophoresis of equal amount of total RNA followed by staining with ethidium bromide). Each PCR reaction contained $1 \mu \mathrm{L}$ of cDNA, $1 \mu \mathrm{M}$ each of forward and reverse primers and sequence detection (MGB) probes, and $12.5 \mu \mathrm{L}$ of universal PCR master mix from Applied Biosystems (Foster City, CA) in a reaction volume of $25 \mu \mathrm{L}$. Reactions were loaded in a 96-well reaction plate and real-time PCR reaction was performed in an ABI Prism 9600 SDS (Applied Biosystems) with the following conditions: $50^{\circ} \mathrm{C} 2$ min, $95^{\circ} \mathrm{C} 10$ min followed by 40 cycles of $57^{\circ} \mathrm{C}$ for $20 \mathrm{~s}, 68^{\circ} \mathrm{C}$ for $40 \mathrm{~s}$, and $95^{\circ} \mathrm{C}$ for $15 \mathrm{~s}$. CT values were determined using the same background subtraction and threshold values for all reactions. For reactions where copy number standards are available, we calculated copy numbers of the gene of interest and GAPDH.

PUFA supplementation in intestinal epithelial cells. Rat small intestinal epithelial cells (IEC-6) were pretreated with or without AA $(100 \mu \mathrm{M})$ or DHA $(67 \mu \mathrm{M})$ (Sigma Chemical Co., St. Louis, MO) for 30 min followed by incubation with $2 \mu \mathrm{M}$ carbamyl-PAF for $4 \mathrm{~h}$. Total RNA was isolated using RNA STAT-60 and PAFR and TLR4 expression levels were evaluated by quantitative real time RT-PCR. Data were expressed as ratio of CT values of gene of interest and $18 \mathrm{~S}$.

Statistical analyses. Power analysis was performed to determine the number of rats required in each treatment group to avoid a Type II error. Using a baseline incidence of $60 \%$, to reduce the incidence of NEC by $50 \%$ and reach significance at $p<0.05$, we calculated that 90 animals were required in each treatment group to ensure a $\beta$ value of 0.8 . $\chi^{2}$ analysis was used to evaluate NEC incidence among the treatment groups using a NEC score of 2 or above. All parametric data were presented as mean \pm SEM. Statistical analyses were performed using ANOVA (GraphPad Prism, San Diego, CA). Differences were considered significant at $p<0.05$.

\section{RESULTS}

PUFA supplementation reduced the incidence of NEC in neonates. Neonatal rats were randomly assigned to four different formula groups immediately after cesarean section. Experiments were carried out to $72 \mathrm{~h}$ although pups often developed signs of distress such as frequent vomiting, cyanosis, and respiratory compromise by $48 \mathrm{~h}$ of life. All three preparations of PUFA reduced the incidence of NEC in this study compared with control formula $(p=0.006)$, as shown in Figure 1. Sub-distribution of rats with specific NEC scores during the course of the study is summarized in Table 2. Histologic analysis and gross examination of intestinal necrosis correlated as in previous studies. Using the Bonferroni

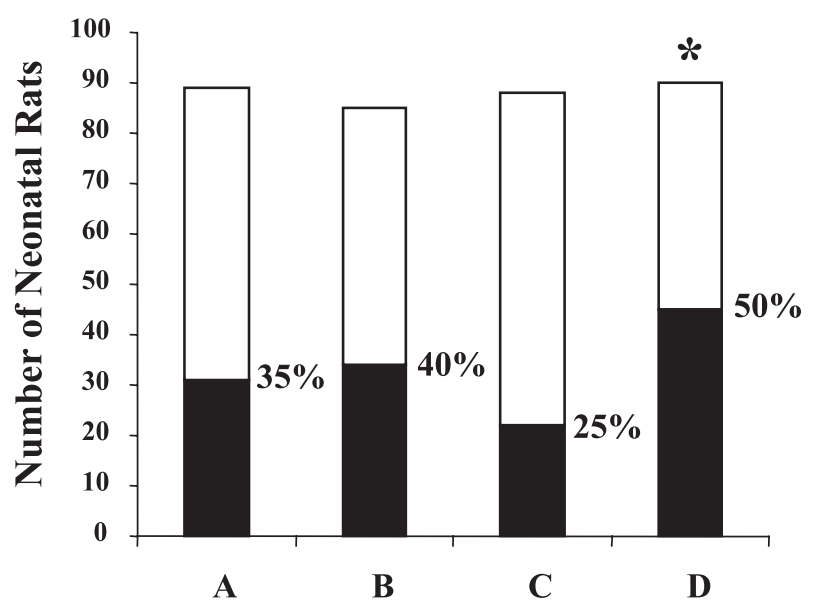

Figure 1. PUFA reduced the incidence of NEC in neonatal rats $(p<0.05)$. Neonatal rats were randomly assigned to four different supplementation groups: A (AA+DHA, $n=89$ ); B (egg phospholipid, $n=85$ ); C (DHA only, $n=88$ ); and $\mathrm{D}$ (control formula, $n=90$ ). Number $(n)$ represents the total neonates in each group. Control formula-fed neonates had significantly higher incidence of NEC than all PUFA-supplemented groups $(p<0.01)$. $\square$ : NEC $(-)$; $:$ NEC (+). 
Table 2. General disease characteristics of neonatal rats fed control, $A A+D H A-, E P-$, and DHA-supplemented formulas

\begin{tabular}{lcccc}
\hline & A & B & C & D \\
& AA + DHA & EP & DHA & Control \\
\hline Histological NEC & & & & \\
$\quad$ Score 2 & 7 & 5 & 6 & 14 \\
Score 3 & 17 & 12 & 9 & 12 \\
Score 4 & 7 & 17 & 7 & 19 \\
Total & $31(89)$ & $34(85)$ & $22(88)$ & $45(90) *$ \\
\hline$p<0.05, \chi^{2}$ analysis. & \\
$*$ Presented as number of incidence (total number of rats evaluated).
\end{tabular}

adjustment, we found that the incidence of NEC in AA+DHA-, EP-, or DHA-supplemented groups did not differ from each other but were all different from that in the control group.

Effect of PUFA supplementation on intestinal TLR2 And TLR4 mRNA expression. Since studies in adult mice (13) have suggested that TLR is differentially expressed across the gastrointestinal tract, we collected four different sections of intestine to identify the effects in duodenum, jejunum, ileum, and colon. TLR2 expression was approximately 10 -fold less in all intestinal segments compared with those of TLR4 (Table 3). The mRNA levels of TLR2 were not affected by PUFA supplementation in jejunum and colon (Table 3). In ileum, TLR2 mRNA levels were lower in neonatal rats fed EP compared with those fed control formula $(p<0.05)$. TLR4 mRNA levels in duodenum, jejunum, and ileum were significantly lower in AA+DHA- and EP- supplemented neonates compared with controls $(p<0.05)$ (Table 3). TLR4 mRNA expression in duodenum, jejunum, and ileum from DHAsupplemented neonates were not different from those of the control neonates (Table 3). Neonates given EP formula had lower colon TLR4 mRNA levels than those given control formula $(p<0.05)$. Colon TLR4 levels in AA+DHA- or DHA-supplemented neonates were not different from the controls. These data suggest that AA containing formula lowers TLR4 expression throughout the whole gut, especially proximal to the colon.

PUFA supplementation down-regulated intestinal PAFR mRNA expression but did not affect intestinal PLA mRNA expression. Because PAF has been implicated in the development of NEC and PAF acts through PAFR to trans- duce signaling to downstream cellular targets, we evaluated the effect of PUFA supplementation on PAFR and PLA ${ }_{2}$-II (the rate-limiting enzyme of PAF production) gene expression by measuring transcription levels. PUFA supplementation from all preparations significantly decreased ileal and colonic, but not duodenal or jejunal, gene expressions of PAFR (Table 4) compared with the control group $(p<0.05)$. Intestinal $\mathrm{PLA}_{2}$-II mRNA levels of AA+DHA-, EP-, or DHAsupplemented neonatal rats were similar to those of controls in all four intestinal segments (Table 5).

AA or DHA supplementation down-regulated PAFinduced TLR4 and PAFR mRNA levels in intestinal epithelial cells (IEC-6). To determine the cellular specificity of the effects observed in in vivo experiments, we studied the effect of PUFA on intestinal epithelial cells using an in vitro system, i.e. IEC-6 cells. Because PAF has been associated with NEC in various models, we sought to determine whether PUFA would alter PAF-induced proinflammatory gene expression in intestinal epithelial cells. We supplemented IEC-6 cells with AA or DHA for 30 min before exposure of $2 \mu \mathrm{M}$ PAF for $4 \mathrm{~h}$ and analyzed TLR4 and PAFR mRNA levels. Here we demonstrated that TLR4 mRNA levels in PAF-treated IEC-6 cells were significantly increased compared with untreated controls (Fig. 2), indicating that in vitro PAF receptor activation regulates TLR4 expression. In addition, TLR4 mRNA expression was significantly lower in IEC-6 cells supplemented with AA $(100 \mu \mathrm{M})$ or DHA $(67 \mu \mathrm{M})$ compared with controls $(p<$ 0.05 ) (Fig. 2, $a$ and $b$ ). After pretreatment of AA or DHA, TLR4 mRNA expression in IEC-6 cells treated with PAF remained at $52 \pm 22 \%$, and $37 \pm 11 \%$ of untreated control $(p<0.05)$ and were significantly lower than those treated with PAF alone $(p<0.05)$. PUFA also inhibited PAFR mRNA expression induced by PAF (Fig. 2, $a$ and $b$ ). PAFR mRNA levels were significantly decreased in IEC-6 cells pretreated with AA (51 $\pm 14 \%$ of untreated control) or DHA (73 $\pm 39 \%$ of untreated control) compared with those treated with PAF alone (both $p<0.05$ ).

\section{DISCUSSION}

Similar to our original report that showed a reduction in experimental NEC with DHA- and AA-supplemented for-

Table 3. The mRNA levels of TLR2 and TLR4 in duodenum, jejunum, ileum, and colon segments expressed as percentage of GAPDH mRNA level

\begin{tabular}{|c|c|c|c|c|}
\hline Treatment & $\begin{array}{c}\mathrm{A} \\
\mathrm{AA}+\mathrm{DHA}\end{array}$ & $\begin{array}{l}\text { B } \\
\text { EP }\end{array}$ & $\begin{array}{c}\text { C } \\
\text { DHA }\end{array}$ & $\begin{array}{c}\mathrm{D} \\
\text { Control }\end{array}$ \\
\hline \multicolumn{5}{|l|}{ TLR2 } \\
\hline Duodenum & $0.2 \pm 0.0(30)^{*}$ & $0.3 \pm 0.1(22)$ & $0.2 \pm 0.0(22)$ & $0.3 \pm 0.0(20)$ \\
\hline Ileum & $0.5 \pm 0.1(34)$ & $0.3 \pm 0.1(24) \dagger$ & $0.4 \pm 0.1(22)$ & $0.6 \pm 0.1(24)$ \\
\hline Colon & $0.6 \pm 0.1(34)$ & $0.6 \pm 0.1(25)$ & $0.7 \pm 0.1(23)$ & $0.8 \pm 0.1(22)$ \\
\hline \multicolumn{5}{|l|}{ TLR4 } \\
\hline Ileum & $2.1 \pm 0.4(34) \dagger$ & $2.1 \pm 0.5(26) \dagger$ & $6.0 \pm 1.1(22)$ & $5.7 \pm 1.0$ \\
\hline Colon & $9.7 \pm 1.1(34)$ & $6.7 \pm 1.6(25) \dagger$ & $16.6 \pm 2.5(23)$ & $14.0 \pm 1.9(24)$ \\
\hline
\end{tabular}

* Presented as mean \pm SEM (number of samples).

$\dagger$ Denotes the data was significantly different from control (control formula $\mathrm{D}, p<0.05$ ). 
Table 4. The mRNA levels of platelet-activating factor receptor in duodenum, jejunum, ileum, and colon segments expressed as percentage of GAPDH $m R N A$ level

\begin{tabular}{ccccc}
\hline & A & B & C & D \\
CP & EP & DHA & \\
Treatment & & & & \\
PAFR & $0.4 \pm 0.0(13)^{*}$ & $0.4 \pm 0.0(14)$ & $0.4 \pm 0.1(14)$ & $0.4 \pm 0.0(12)$ \\
Duodenum & $0.5 \pm 0.0(13)$ & $0.5 \pm 0.0(13)$ & $0.6 \pm 0.0(14)$ & $0.5 \pm 0.0(13)$ \\
Jejunum & $0.5 \pm 0.0(13) \dagger$ & $0.5 \pm 0.1(13) \dagger$ & $0.5 \pm 0.0(11) \dagger$ & $0.7 \pm 0.0(13)$ \\
Ileum & $0.4 \pm 0.0(12) \dagger$ & $0.5 \pm 0.0(14) \dagger$ & $0.4 \pm 0.0(12) \dagger$ & $0.6 \pm 0.0(13)$ \\
Colon & & &
\end{tabular}

* Presented as mean \pm SEM (number of samples).

$\dagger$ Denotes the data was significantly different from control (control formula $\mathrm{D}, p<0.05$ ).

Table 5. The mRNA levels of PLA, in duodenum, jejunum, ileum, and colon segments expressed as percentage of GAPDH mRNA level

\begin{tabular}{ccccc}
\hline Treatment & A & B & C & Control \\
AA+DHA & EP & DHA & & D \\
\hline PLA $_{2}$ & & & & \\
Duodenum & $0.6 \pm 0.2(16)^{*}$ & $4.0 \pm 1.4(13)$ & $2.2 \pm 1.1(11)$ & $0.9 \pm 0.3(12)$ \\
Jejunum & $2.2 \pm 1.1(17)$ & $4.6 \pm 1.7(13)$ & $2.8 \pm 0.8(10)$ & $3.4 \pm 1.1(13)$ \\
Ileum & $2.9 \pm 1.0(17)$ & $4.4 \pm 1.1(12)$ & $7.1 \pm 1.5(11)$ & $4.9 \pm 1.5(12)$ \\
Colon & $11.6 \pm 1.7(17)$ & $16.2 \pm 4.3(11)$ & $19.7 \pm 5.8(11)$ & $17.3 \pm 3.6(13)$ \\
\hline
\end{tabular}

* Presented as mean \pm SEM (number of samples).

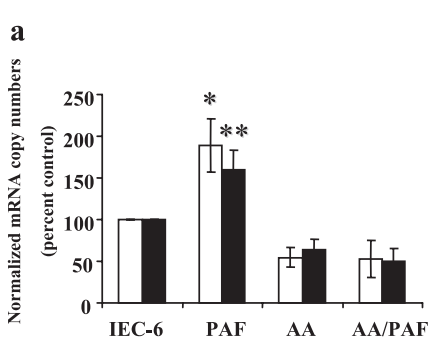

b

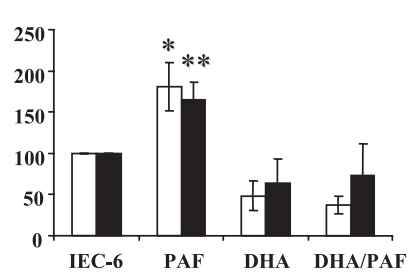

Figure 2. Pretreatment with PUFA in IEC-6 cells reduced PAF-induced TLR4 ( $\square$ ) and PAFR (ם) expression. Data were presented as a relative change based on RT-PCR data compared with control IEC-6 cells. After pretreatment of AA $(a)$, or DHA $(b)$, TLR4 mRNA expressions in IEC-6 cells treated with PAF were significantly lower than those of untreated controls and treated with PAF alone (all $p<0.05$ ). PUFA also inhibited PAFR mRNA expression induced by PAF. PAFR mRNA levels were significantly decreased in IEC-6 cells pretreated with AA or DHA compared with those treated with PAF alone (both $p<0.05$ ). ${ }^{*} p<0.01$ compared with untreated controls; $* * p<0.05$ compared with untreated controls.

mula, here we demonstrate that pups fed with three different preparations of PUFA all developed less NEC than control formula-fed animals. In addition, gut expression of PAFR and TLR4 in PUFA-supplemented formula-fed pups were significantly reduced compared with controls. In vitro experiments confirmed that AA or DHA pretreatment lowered baseline expression of TLR4 in cultured intestinal epithelial cells and blocked PAF-induced PAFR and TLR4 expression. Together, these observations suggest potential benefits of PUFA in modulating gut injury in neonatal NEC.

Since the early 1990s, several studies have examined the impact of DHA or DHA plus AA supplementation on visual function and neurodevelopmental outcome in preterm and full-term neonates (14). Although there have been conflicting reports, many experiments have supported a beneficial effect using these preparations. One concern suggested in some reviews was the potential of oxidative damage-related neonatal conditions (e.g. NEC, bronchopulmonary dysplasia, and retinopathy of prematurity) resulting from the supplementa- tion with highly unsaturated fatty acids. The ratio of n-3 and n-6 fatty acids was another concern in view of the possible effects on eicosanoid metabolism with resulting effects on blood clotting and infection. In terms of NEC, in Carlson and colleagues' earlier study (15) there was no significant difference in NEC between the supplemented and control groups. Lucas et al. (16) reported a higher combined incidence of NEC and sepsis in the supplemented than in the unsupplemented group. In a later study, Carlson (5) found that in infants fed a formula supplemented with egg yolk phospholipid containing $0.4 \%$ AA, $0.13 \%$ DHA, and about 3-fold more total choline, the incidence of NEC was significantly lower than controls. It was suggested that AA and choline containing formula might contribute to maintenance of intestinal blood flow and cytoprotection of intestinal mucosa. Differences in these outcomes are difficult to interpret due to multiple factors that highlight the complexity of human trials. In vivo, we demonstrated earlier that neonates fed a preterm formula containing $0.7 \% \mathrm{AA}$ and $0.5 \% \mathrm{DHA}$ had a lower incidence of NEC using a neonatal rat model. In this study, we confirmed that PUFA supplementation of preterm formula reduced the incidence of NEC in our neonatal rat model, and that the beneficial effects of PUFA appear to be equally significant in all PUFA preparations tested. As detailed in Table 1, all three PUFA-supplemented formulas had similar DHA content. The two AA-containing formulas had the same amount and ratio of AA and DHA. These data, together with the previous clinical trials, suggest that relatively low concentrations of AA and DHA in formula and the appropriate ratio of the two fatty acids might be beneficial and safe.

Altered PAF metabolism has been associated with NEC in human studies and animal experiments $(3,4)$. For example, using the same NEC animal model we used in the present study, pups treated with the PAFR antagonist WEB 2170 and PAF-degrading enzyme PAF-AH had a lower incidence of NEC. Furthermore, newborns are deficient in serum PAF-AH activity, and preterm infants without NEC have higher 
PAF-AH activity and lower circulating PAF compared with those who develop intestinal necrosis. PUFA supplementation did not affect PLA $_{2}$-II intestinal mRNA expression, but all preparations reduced mRNA expression of PAFR in ileum and colon. These findings were confirmed in vitro where PUFA supplementation down-regulated PAFR expression in cultured enterocytes. Therefore, we speculate that modulation of PAFR production and decreased PAFR signaling in the gut might contribute to the beneficial role of PUFA in intestinal health.

Human TLRs are a family of pattern recognition molecules found in cells responding to bacterial ligands. In mammals, 11 TLRs have been identified $(17,18)$ and the agonists for TLR activation vary. For example, TLR4 is the dominant receptor for Gram-negative endotoxin LPS (19-21) and TLR2 responds to other bacterial cell wall components like lipoteichoic acid (22). Our data here demonstrate that PAF is a potent inducer of TLR4 gene expression in rat intestinal epithelial cells, and our recent paper highlights the importance of TLR4 in neonatal experimental NEC (23). Recently, Lee et al. (24) reported that contrary to saturated fatty acids such as lauric acid and palmitic acid, long-chain unsaturated fatty acids inhibited NF- $\kappa$ B activation induced by LPS or lipopeptide, a synthetic TLR2 agonist in macrophages. Lipid A, a functional component of LPS, is normally acylated with saturated fatty acids. Deacylated bacterial lipoproteins or lipoprotein containing PUFA lose their toxicity and ability to activate TLR (25), thereby providing a mechanism for potential protection. Together with early observations that $\mathrm{C} 3 \mathrm{H} / \mathrm{HeJ}$ mice containing a mutation in their TLR4 gene are resistant to PAF-induced intestinal injury (26) and PAF antagonists could block LPS-induced ischemic bowel necrosis $(27,28)$, we investigated whether these PUFA modulate TLR expression in the neonatal intestine. We present here for the first time that, in neonatal rats, AA-containing formulas can modulate the TLR4 mRNA expression along the whole small intestine. PUFA supplementation did not alter TLR2 expression, highlighting the specificity of this effect on TLR4.

The mechanisms by which PUFA provide protective effects on intestinal epithelium are undoubtedly complex. PUFA can affect gene expression through various mechanisms including its action on the nucleus, in conjunction with nuclear receptors and transcription factors, such as the peroxisome proliferatoractivated receptor, hepatocyte nuclear factor- $4 \alpha$, liver X receptor, the transcription factors sterol-regulatory element binding protein, and NF- $\kappa \mathrm{B}$ (29). Of interest, in our study, DHA decreased PAFR gene expression in ileum and colon but had no effect on TLR4 gene expression throughout the gut, whereas AA- and DHA-containing formula altered both PAFR and TLR4 gene expression. In addition, novel n-3 fatty acid (namely eicosapentaenoic acid, or DHA itself) derived lipid mediators (resolvins and protectins) are believed to be anti-inflammatory by mainly attenuating the NF- $\kappa \mathrm{B}$ pathway (30-33). Because of the complexity of our in vivo model that includes multiple cell types and interacting factors, the specific mechanisms of different PUFA preparations on intestinal homeostasis are difficult to determine.

Another potential mechanism explaining PUFA's antiinflammatory effects may be the ability to directly affect
G-protein-coupled receptor signaling by altering one of the protein posttranslational modifications-palmitoylation. Studies have shown that PUFA can modify GPCR signaling by directly interrupting palmitoylation on receptors and $\mathrm{G}$ proteins (34) or decreasing ligand binding (35). PAFR is a G-protein-coupled receptor and in vitro we have shown that PAFR is palmitoylated and both AA and DHA can inhibit the incorporation of palmitate into PAFR (unpublished data). Functional assays revealed that blocking palmitoylation by 2-bromo palmitate or PUFA decreased PAFR signaling as measured by reduced PAF-induced ion transport, apoptosis, and gene expression in intestinal epithelial cells. The evidence supports the notion that in addition to their effects on prostaglandin biosynthesis, disruption of G-protein-coupled receptor signaling might be another mechanism by which PUFA exert their effects.

In summary, all preparations of PUFA supplementation tested in this study significantly lowered the incidence of NEC in our neonatal rat NEC model. PUFA specifically downregulated PAFR gene expression in the ileum and colon, suggesting a possible mechanism for the protective effect on intestinal injury. Our data further suggest that the robust inflammatory responses induced by the activation of TLR 4 on neonatal intestinal epithelium via bacterial colonization might be modulated by certain long-chain polyunsaturated fatty acid preparations. This may be an additional mechanism responsible for PUFA's protective effects on neonatal NEC. Further understanding of the interactions between PAFR, TLR signaling, and PUFA is warranted to delineate the protective role of these anti-inflammatory fatty acids and the pathophysiology of NEC.

Acknowledgments. The authors thank Dr. Kurt Steiner for support in this work.

\section{REFERENCES}

1. Caplan MS, Jilling T 2001 New concepts in necrotizing enterocolitis. Curr Opin Pediatr 13:111-115

2. MacKendrick W, Caplan M 1993 Necrotizing enterocolitis. New thoughts about pathogenesis and potential treatments. Pediatr Clin North Am 40:1047-1059

3. Caplan MS, Hedlund E, Adler L, Lickerman M, Hsueh W 1997 The plateletactivating factor receptor antagonist WEB 2170 prevents neonatal necrotizing enterocolitis in rats. J Pediatr Gastroenterol Nutr 24:296-301

4. Caplan MS, Lickerman M, Adler L, Dietsch GN, Yu A 1997 The role of recombinant platelet-activating factor acetylhydrolase in a neonatal rat model of necrotizing enterocolitis. Pediatr Res 42:779-783

5. Carlson SE, Montalto MB, Ponder DL, Werkman SH, Korones SB 1998 Lower incidence of necrotizing enterocolitis in infants fed a preterm formula with egg phospholipids. Pediatr Res 44:491-498

6. Fewtrell MS, Morley R, Abbott RA, Singhal A, Isaacs EB, Stephenson T, MacFadyen U, Lucas A 2002 Double-blind, randomized trial of long-chain polyunsaturated fatty acid supplementation in formula fed to preterm infants. Pediatrics 110:73-82

7. Caplan MS, Russell T, Xiao Y, Amer M, Kaup S, Jilling T 2001 Effect of polyunsaturated fatty acid (PUFA) supplementation on intestinal inflammation and necrotizing enterocolitis (NEC) in a neonatal rat model. Pediatr Res 49:647-652

8. Akisu M, Baka M, Coker I, Kultursay N, Huseyinov A 1998 Effect of dietary n-3 fatty acids on hypoxia-induced necrotizing enterocolitis in young mice. n-3 fatty acids alter platelet-activating factor and leukotriene B4 production in the intestine. Biol Neonate 74:31-38

9. Watanabe S, Doshi M, Akimoto K, Kiso Y, Hamazaki T 2001 Suppression of platelet-activating factor generation and modulation of arachidonate metabolism by dietary enrichment with (n-9) eicosatrienoic acid or docosahexaenoic acid in mouse peritoneal cells. Prostaglandins Other Lipid Mediat 66:109-120

10. Moon Y, Pestka JJ 2003 Deoxynivalenol-induced mitogen-activated protein kinase phosphorylation and IL-6 expression in mice suppressed by fish oil. J Nutr Biochem $14: 717-726$ 
11. Lee JY, Zhao L, Youn HS, Weatherill AR, Tapping R, Feng L, Lee WH, Fitzgerald KA, Hwang DH 2004 Saturated fatty acid activates but polyunsaturated fatty acid inhibits Toll-like receptor 2 dimerized with Toll-like receptor 6 or 1. J Biol Chem 279:16971-16979

12. Jilling T, Lu J, Jackson M, Caplan MS 2004 Intestinal epithelial apoptosis initiates gross bowel necrosis in an experimental rat model of neonatal necrotizing enterocolitis. Pediatr Res 55:622-629

13. Ortega-Cava CF, Ishihara S, Rumi MA, Kawashima K, Ishimura N, Kazumori H, Udagawa J, Kadowaki Y, Kinoshita Y 2003 Strategic compartmentalization of Toll-like receptor 4 in the mouse gut. J Immunol 170:3977-3985

14. Klein CJ Nutrient requirements for preterm infant formulas. J Nutr 132:1395S1549S, 2002.

15. Carlson SE, Ford AJ, Werkman SH, Peeples JM, Koo WW 1996 Visual acuity and fatty acid status of term infants fed human milk and formulas with and without docosahexaenoate and arachidonate from egg yolk lecithin. Pediatr Res 39:882-888

16. Lucas A, Quinlan P, Abrams S, Ryan S, Meah S, Lucas PJ 1997 Randomised controlled trial of a synthetic triglyceride milk formula for preterm infants. Arch Dis Child Fetal Neonatal Ed 77:F178-F184

17. Medzhitov R, Preston-Hurlburt P, Janeway CA Jr 1997 A human homologue of the Drosophila Toll protein signals activation of adaptive immunity. Nature 388:394-397.

18. Zarember KA, Godowski PJ 2002 Tissue expression of human Toll-like receptors and differential regulation of Toll-like receptor mRNAs in leukocytes in response to microbes, their products, and cytokines. J Immunol 168:554-561

19. Poltorak A, He X, Smirnova I, Liu MY, Van Huffel C, Du X, Birdwell D, Alejos E, Silva M, Galanos C, Freudenberg M, Ricciardi-Castagnoli P, Layton B, Beutler B 1998 Defective LPS signaling in $\mathrm{C} 3 \mathrm{H} / \mathrm{HeJ}$ and C57BL/10ScCr mice: mutations in Tlr4 gene. Science 282:2085-2088

20. Qureshi ST, Lariviere L, Leveque G, Clermont S, Moore KJ, Gros P, Malo D 1999 Endotoxin-tolerant mice have mutations in Toll-like receptor 4 (Tlr4). J Exp Med 189:615-625

21. Rhee SH, Hwang D 2000 Murine TOLL-like receptor 4 confers lipopolysaccharide responsiveness as determined by activation of NF kappa B and expression of the inducible cyclooxygenase. J Biol Chem 275:34035-34040

22. Aderem A, Ulevitch RJ 2000 Toll-like receptors in the induction of the innate immune response. Nature 406:782-787

23. Jilling T, Simon D, Lu J, Meng FJ, Li D, Schy R, Thomson RB, Soliman A, Arditi M, Caplan MS 2006 The roles of bacteria and TLR4 in rat and murine models of necrotizing enterocolitis. J Immunol 177:3273-3282
24. Lee JY, Plakidas A, Lee WH, Heikkinen A, Chanmugam P, Bray G, Hwang DH 2003 Differential modulation of Toll-like receptors by fatty acids: preferential inhibition by n-3 polyunsaturated fatty acids. J Lipid Res 44:479-486

25. Brightbill HD, Libraty DH, Krutzik SR, Yang RB, Belisle JT, Bleharski JR, Maitland M, Norgard MV, Plevy SE, Smale ST, Brennan PJ, Bloom BR, Godowski PJ, Modlin RL 1999 Host defense mechanisms triggered by microbial lipoproteins through toll-like receptors. Science 285:732-736

26. Sun X, Caplan MS, Liu Y, Hsueh W 1995 Endotoxin-resistant mice are protected from PAF-induced bowel injury and death. Role of TNF, complement activation, and endogenous PAF production. Dig Dis Sci 40:495-502

27. Hsueh W, Gonzalez-Crussi F, Arroyave JL 1987 Platelet-activating factor: an endogenous mediator for bowel necrosis in endotoxemia. FASEB J 1:403405

28. Caplan MS, Kelly A, Hsueh W 1992 Endotoxin and hypoxia-induced intestinal necrosis in rats: the role of platelet activating factor. Pediatr Res 31:428 434

29. Sampath H, Ntambi JM 2005 Polyunsaturated fatty acid regulation of genes of lipid metabolism. Annu Rev Nutr 25:317-340

30. Serhan CN 2002 Lipoxins and aspirin-triggered 15-epi-lipoxin biosynthesis: an update and role in anti-inflammation and pro-resolution. Prostaglandins Other Lipid Mediat 68-69:433-455

31. Serhan CN, Savill J 2005 Resolution of inflammation: the beginning programs the end. Nat Immunol 6:1191-1197

32. Arita M, Yoshida M, Hong S, Tjonahen E, Glickman JN, Petasis NA, Blumberg RS Serhan CN 2005 Resolvin E1, an endogenous lipid mediator derived from omega-3 eicosapentaenoic acid, protects against 2,4,6-trinitrobenzene sulfonic acid-induced colitis. Proc Natl Acad Sci U S A 102:7671-7676

33. Arita M, Bianchini F, Aliberti J, Sher A, Chiang N, Hong S, Yang R, Petasis NA, Serhan CN 2005 Stereochemical assignment, antiinflammatory properties, and receptor for the omega-3 lipid mediator resolvin E1. J Exp Med 201:713722

34. Hallak H, Muszbek L, Laposata M, Belmonte E, Brass LF, Manning DR 1994 Covalent binding of arachidonate to $\mathrm{G}$ protein alpha subunits of human platelets. J Biol Chem 269:4713-4716

35. Bordayo EZ, Fawcett JR, Lagalwar S, Svitak AL, Frey WHJr 2005 Inhibition of ligand binding to $\mathrm{G}$ protein-coupled receptors by arachidonic acid. J Mol Neurosci 27:185-194 